\title{
Formação e prática didático-pedagógicas de professores dos cursos de Tecnologia em Radiologia
}

Training and pedagogical practice of teachers of Radiology Technology courses

\author{
Érica Natasha Duarte Silva (D) https://orcid.org/0000-0002-4182-2137 \\ Instituto Federal do Piauí (IFPI) \\ E-mail: ericanatasha@hotmail.com
}

Ednaldo Francisco Santos O. Junior (iD https://orcid.org/0000-0002-9977-3948

Instituto Federal do Piauí (IFPI)

E-mail: ednaldojunior.oliveira@bol.com.br

\author{
Maria da Glória Duarte Ferro (iD https://orcid.org/0000-0002-5473-3256 \\ Universidade Federal do Piauí (UFPI) \\ E-mail: gloria-ferro@hotmail.com
}

\section{Resumo}

O corpo docente dos cursos de Tecnologia em Radiologia é formado majoritariamente por Bacharéis e Tecnólogos, estes professores não têm em sua graduação, disciplinas voltadas à docência, portanto não são, profissionalmente, preparados para atuarem como professor na sua formação inicial. Dessa forma, é comum que dificuldades surjam no processo ensinoaprendizagem, especialmente no início da atividade docente. Esta pesquisa tem como objetivo identificar as necessidades formativas para desenvolvimento de práticas didático-pedagógicas de professores dos cursos de Tecnologia em Radiologia, analisando e refletindo sobre o perfil destes docentes relacionando ao processo ensino-aprendizagem emergentes das suas práticas em sala de aula. Trata-se de uma revisão bibliográfica, onde procurou-se entender o perfil dos docentes dos cursos de Tecnologia em Radiologia e associar às suas práticas docentes e necessidades formativas. Foi realizado um estudo a partir de artigos publicados nas bases de dados Scielo, Lilacs e Pubmed no período 1998 a 2020 no idioma português, a partir da combinação dos descritores: Docente, Formação Inicial, Formação Pedagógica, Práticas Didático-pedagógicas, Processo Ensino-aprendizagem. Observou-se que o conhecimento pedagógico isoladamente não consegue tornar o processo ensino-aprendizado eficaz, uma vez que o domínio técnico e científico colabora ativamente com a construção das bases tecnológicas repassadas aos discentes. $O$ professor do curso de Tecnologia em Radiologia precisará contemplar conhecimento científico, técnico, prático e pedagógico para aprimorar o desempenho em seu trabalho docente. É importante que o professor prossiga na formação continuada e faça um aprofundamento teóricometodológico dos conhecimentos em sua formação profissional além da aquisição de conhecimentos pedagógicos.

Palavras-chave: Docente. Formação pedagógica. Curso superior de tecnologia. Didáticopedagógica. Processo ensino-aprendizagem.

\section{Abstract}


The faculty of the Radiology Technology courses is formed mainly by Bachelor and Technologists, these professors do not have in their graduation, disciplines focused on teaching, therefore they are not professionally prepared to act as a teacher in their initial training. Thus, it is common for difficulties to arise in the teaching-learning process, especially at the beginning of teaching activity. This research aims to identify the training needs for the development of didactic-pedagogical practices of teachers of Technology in Radiology courses, analyzing and reflecting on the profile of these teachers relating to the teaching-learning process emerging from their classroom practices. This is a bibliographic review, in which it was sought to understand the profile of teachers in the Radiology Technology courses and to associate them with their teaching practices and training needs. A study was carried out based on articles published in the databases: Scielo, Lilacs and Pubmed in the period 1998 to 2018, in Portuguese, using the combination of descriptors: Teacher, Initial Training, Pedagogical Training, Didactic-pedagogical Practices, Process Teaching-learning. It was observed that the pedagogical knowledge alone cannot make the teaching-learning process effective, since the technical and scientific domain actively collaborates with the construction of the technological bases passed on to the students. The professor of the Radiology Technology course will need to contemplate scientific, technical, practical and pedagogical knowledge to improve the performance in his teaching work. It is important that the teacher proceeds with continuing education and does a theoretical-methodological deepening of the knowledge in his professional training in addition to the acquisition of pedagogical knowledge.

Keywords: Teacher. Pedagogical training. Higher education in technology. Didacticpedagogical.Teaching-learning process.

\section{Introdução}

O conhecimento científico e técnico do professor é, sem dúvida, de extrema importância, pois este deverá ser repassado ao aluno, porém, o conhecimento pedagógico é o responsável, de fato, pelo processo ensino-aprendizagem. Parte deste conhecimento é construído na prática docente, sendo que o estudo e a pesquisa da prática didático-pedagógica são essenciais. Até aproximadamente metade do século $X X$, não havia nenhuma forma de educação formal destinada a qualificar profissionais, auxiliares ou tecnólogos da área de radiologia, talvez por serem categorias ainda pouco desenvolvidas (OLIVEIRA et al., 2013).

Com a expansão da categoria profissional do auxiliar médico radiologista, houve necessidade de formação destes profissionais e em 1968, foi criado o primeiro curso público para operadores de raios $X$ no Instituto Estadual de Radiologia e Medicina Nuclear Manoel de Abreu (IERMN), no Rio de Janeiro, onde os docentes eram predominantemente médicos, segundo Oliveira et al. ( 2013).

Mais recentemente surgiram os cursos superiores de tecnologia, inclusive na área da Radiologia, estes vieram com o objetivo de atender uma demanda existente de profissionais de nível superior que atuassem nos meios produtivos. Isso talvez, explique a tendência de se dar tanta importância a formação técnica dos professores que atuam nestes cursos, já que o conhecimento científico e prático é o principal resultado almejado. Esse conhecimento técnico tem por objetivo a solução de problemas existentes no universo profissional dos meios produtivos, ou seja, a aplicação prática dos conhecimentos no exercício da profissão (SIEWERDT; RAUSCH, 2018). 
Levando em consideração o trabalho docente e as práticas pedagógicas, o saber e a prática docente são compostos por vários níveis de complexidade. $O$ trabalho do professor em sala de aula envolve aspectos culturais, sociais e históricos. A ação educativa ocorre de forma sistematizada pela interação destes fatores, dessa forma, tanto a escola como o ambiente de trabalho, são espaços adequados para desenvolver o ato educativo (SANTOS; OLIVEIRA, 2016).

É importante entender que mesmo os professores graduados em Radiologia atuando, em sua maioria, na prática das técnicas radiológicas, também precisam de uma formação avançada e não somente uma perspectiva especializada que complemente o conhecimento. De acordo com Santos e Oliveira (2016), a formação do professor para a educação profissional, assim como para toda formação docente, deve priorizar o domínio do trabalho e desenvolvimento intelectuais favorecendo a capacidade de criação de novos conhecimentos e conceitos relacionados a uma determinada prática.

Atualmente a formação de Tecnólogos em Radiologia é oferecida, em sua maioria, nas escolas privadas, e tem o corpo docente formado majoritariamente, por Bacharéis e Tecnólogos, e geralmente, não há exigência de formação em Docência para atuação destes professores (OLIVEIRA et al., 2013).

É nesta perspectiva que se objetiva identificar quais as necessidades formativas para desenvolvimento de práticas didático-pedagógicas de professores dos cursos de Tecnologia em Radiologia, analisando e refletindo sobre o perfil destes docentes e de suas práticas didático-pedagógicas, caracterizando-as, identificando as dificuldades na atuação do professor sem formação docente e relacionando esta formação com o processo ensino-aprendizagem emergentes das práticas docentes.

\section{Metodologia}

Este estudo trata-se de uma revisão de literatura, no qual procurou-se entender o perfil dos docentes dos cursos de Tecnologia em Radiologia e associar às suas práticas docentes e necessidades formativas.

Foi realizado um levantamento de artigos publicados nas bases de dados Scielo, Lilacs e Pubmed no período 1998 a 2020 a partir da combinação dos descritores Docente, Formação Inicial, Formação Pedagógica, Práticas Didático-pedagógicas, Processo Ensino-aprendizagem e Tecnologia em Radiologia, utilizando o operador booleano "OR" e "AND" para ligação entre os termos.

Foram analisadas as publicações que obedeceram aos critérios de inclusão, como artigos com disponibilidade na íntegra, com os termos identificados ou os descritores relacionados entre si, idioma português e com data de publicação entre 1998 a 2020 cujos títulos e/ou objetivos possuam ligação com a temática e o objetivo de estudo. Foram excluídos aqueles que destoaram do tema e objetivo do estudo e que estavam fora do período determinado.

A busca totalizou 53 artigos, dos quais apenas 19 atenderam aos critérios de inclusão, sendo publicados entre 1998 e 2020 e com relevância para atingir o objetivo. Por fim, os dados foram organizados, analisados e interpretados conforme os objetivos do estudo e de acordo com a literatura consultada. 


\section{A história do ensino superior e sua relação com as necessidades formativas dos professores deste nível de ensino}

Os primeiros cursos superiores do Brasil seguiam o modelo universitário no padrão francês napoleônico, caracterizado por escolas autárquicas com uma supervalorização das ciências exatas e tecnológicas e a consequente desvalorização da filosofia, da teologia e das ciências humanas. Desta forma, as instituições de ensino superior criadas e instaladas no Brasil, desde o seu início, voltaram-se diretamente para a formação de profissionais que exerceriam uma determinada profissão. Os currículos eram seriados, programas fechados, que constavam somente as disciplinas que interessavam imediata e diretamente ao exercício daquela profissão (LUCCHESI, 2011).

Os cursos formavam seus profissionais por um processo de ensino onde conhecimentos e experiências profissionais são transmitidos de um professor que sabe e conhece para um aluno que não sabe e não conhece, seguido de uma avaliação que diz se o aluno está apto ou não para exercer aquela profissão (MASETTO, 1998).

As Instituições procuravam profissionais renomados, com sucesso em suas atividades profissionais e os convidavam a ensinar seus alunos a serem tão bons profissionais como eles. Até a década de 70, segundo Masetto (1998), exigia-se do candidato a professor de ensino superior o bacharelado e o exercício competente de sua profissão.

Esta origem do ensino superior no Brasil explica em partes, a crença ainda existente de que o professor que domina o conhecimento científico, necessariamente sabe ensinar. A docência, nem sempre é reconhecida pelo bacharel e/ou tecnólogo como profissão porque ela "apenas complementa a renda" e isso passa pela questão de status e pela desvalorização salarial do professor, nos termos de Almeida e Pimenta (2011).

As instituições não exigem do professor uma formação pedagógica, bastando, na maioria das vezes, a quantidade de títulos não necessariamente voltados para a docência; esse conjunto de fatores faz o modelo francês napoleônico aparecer no Ensino Superior atual, ainda que de forma bem mais discreta (ALMEIDA; PIMENTA, 2011).

Somente recentemente os professores universitários começaram a se conscientizar de que a docência, como pesquisa e o exercício de qualquer profissão, exige capacitação própria e específica. O exercício docente no ensino superior exige competências específicas, que não se restringem a ter um diploma de bacharel, mestre ou doutor, ou, ainda, apenas o exercício de uma profissão (MASETTO, 1998).

Oliveira e Silva (2012) afirmam que as problemáticas que se referem à formação de professores universitários se aproximam das que envolvem a formação do docente do campo da Educação profissional, por existirem características semelhantes no perfil formativo e profissional dos bacharéis que atuam como professores nesses campos. Assim, esta abordagem das necessidades formativas se encaixa para professores sem formação docente. 
Estes professores não têm, em sua graduação, disciplinas voltadas à docência, portanto não são, profissionalmente, preparados para atuarem como professor na sua formação inicial, sendo comum que dificuldades surjam no processo ensinoaprendizagem, especialmente no início da atividade docente, já que o conhecimento pedagógico não ocorre na sua formação (OLIVEIRA; SILVA, 2012). Cabe ressaltar que apesar disso, a atuação dos professores bacharéis e tecnólogos no Ensino Superior tem sido significativa.

Segundo Lima (2015), as necessidades formativas de docentes podem ser reveladas por meio de três polos: o da representação da situação atual, expressa em termo de problemas, disfunções, exigências, dificuldades, defeitos; o da representação da situação esperada, manifestada por desejo, aspiração, motivação; e o da representação das perspectivas de ação, nas quais as necessidades se exprimem por meio de ações a serem realizadas. Qualquer que seja a forma de se revelar a necessidade, o importante é que ela seja descoberta e sanada, entendendo-se o docente como detentor de grande responsabilidade na educação e formação profissional de seus alunos.

De acordo com Oliveira e Silva (2012), espera-se que esse profissional reflita sobre suas ações e busque inovar suas práticas, aprimorando seus conhecimentos e práticas pedagógicas para que possam proporcionar uma formação crítica e atuando de forma que seus alunos possam exercer sua cidadania com base nos conhecimentos e habilidade apreendidos neste século $\mathrm{XXI}$.

Alarcão (2003) ao defender a necessidade de os professores desenvolverem uma prática baseada na reflexão sobre a ação, diz que na escola e nos professores, a constante atitude de reflexão manterá presente a importante questão da função que os professores e a escola desempenham na sociedade e ajudará a resolver dilemas e problemas.

$\mathrm{Na}$ perspectiva da referida autora, a reflexão torna-se um elemento importante para o processo de formação e atuação docente, sendo também relevante essa postura nos âmbitos acadêmicos, além de permitir ao docente outras possibilidades de ação e de formação, visando atender à necessidade social de uma formação que não privilegia somente os aspectos técnicos para o mundo do trabalho, mas também apresenta-se como humanística, integral incorporando ciência, trabalho, tecnologia e cultura como eixos indissociáveis.

Desta forma, o docente deverá ser capaz de ajustar suas práticas e seus conhecimentos às novas exigências da sociedade, do aluno, dos diversos universos culturais, das formas de comunicação presentes, pois são esses seus elementos de trabalho que também sofreram e estão em constantes modificações (ALARCÃO, 2003).

Nessa mesma linha de raciocínio Oliveira e Silva (2012) observam que os docentes de Ensino Superior necessitam entender que seu conhecimento deve estar em constante ressignificação, para que seja desenvolvida uma postura de professor transformador que reflete sobre sua prática, questionando, pensando, criticando, buscando soluções, refazendo conceitos, já que as transformações e mudanças afetam toda a comunidade, inclusive o meio acadêmico.

Assim, fica claro a importância da formação pedagógica como pré-requisito para o exercício da docência, o que torna necessário a revisão das formas de admissão 
de novos professores nas Universidades e nos Institutos Federais de Educação, Ciência e Tecnologia. Muitas vezes, o que se valoriza nos processos seletivos de admissão, são os conhecimentos específicos do professor em relação a sua área de formação, bem como sua experiência profissional e titulações na área comum de formação inicial.

De acordo com a Lei n 9.394/96, de Diretrizes e Bases da Educação Nacional, a formação do docente do ensino propedêutico de fundamento generalista, compreensivo das bases do conhecimento humano, é realizada por meio de cursos de licenciatura nas instituições de educação superior (IES), universidades, centros universitários e faculdades isoladas.

A formação técnico-pedagógica é apenas recomendada na educação profissional, tecnológica e superior. Ou seja, os estudos propedêuticos requerem professores com formação teórica e metodológica consistente, portanto pedagogicamente preparados para a sua condução, enquanto os estudos profissionais e tecnológicos dispensam os saberes da docência (CARVALHO; SOUZA, 2014).

O recente Parecer CNE/CP n' 7/2020, de 19 de maio de 2020, capítulo XVII, artigo $n^{\circ} 57$, preconiza que a formação do docente da Educação Profissional e Tecnológica, além do bom domínio dos saberes pedagógicos necessários para conduzir o processo de aprendizagem de estudantes, requer o desenvolvimento de saberes e competências profissionais, associados ao adequado domínio dos diferentes saberes disciplinares referentes ao campo específico de sua área.

A legislação exige que o professor que atua em cursos de graduação, tenha alguma especialização em nível lato sensu e mais 90 horas de complementação em disciplinas didático-pedagógicas e metodológicas, e sua graduação não precisa, necessariamente, ser da mesma área do ensino em que vai atuar. Assim, o direcionamento para a docência fica à critério das instituições de ensino onde estes professores atuam. Como observam SIEWERDT e RAUSCH (2018), a lei prevê que um professor pode lecionar em um curso totalmente diferente da sua formação, dessa forma o professor fica sujeito a lecionar em áreas desconhecidas.

Os cursos superiores continuam cumprindo o papel de atenderem a demanda de profissionais para a indústria e, neste sentido, são estratégicos ao país. Diferentemente dos outros níveis de ensino, os professores bacharéis e tecnólogos se constituem, historicamente, tendo como base a profissão paralela que exerce ou exercia no mundo do trabalho. A ideia de quem sabe fazer, sabe ensinar sustentou e sustenta a lógica do recrutamento dos docentes, portanto, dando-se maior importância a sua carreira profissional em detrimento da sua formação docente (SIEWERDT; RAUSCH, 2018).

Os professores do ensino superior geralmente não têm formação prévia e específica no que diz respeito à docência, o início da trajetória profissional destes docentes, por vezes, ocorre de forma precária. Eles assumem os encargos docentes respaldados nos modelos de mestres que fizeram parte de sua formação inicial, aliados a conhecimentos oriundos de determinado campo científico e da prática como profissionais de uma atividade que não a do magistério superior. No ensino superior parte-se do princípio de que sua competência docente é originada do domínio da área de conhecimento na qual atua (PEREIRA, 2015).

Siewerdt e Rausch (2018) afirmam que os profissionais devem se apoiar em sua prática em conhecimentos especializados e formalizados, na maioria das vezes, 
por intermédio das disciplinas científicas em sentido amplo, incluindo as ciências naturais e aplicadas, mas também nas ciências sociais e humanas, assim como nas ciências da educação.

Um fator de grande importância em relação ao exercício da docência está na capacidade de o professor refletir sobre sua própria atuação, e esta postura reflexiva depende em muito da sua formação. A reflexividade gera no professor a capacidade de flexibilidade diante das diversas situações e dinâmicas às quais está sujeito na sala de aula. Nesse sentido, é importante chamar atenção para o fato de que, apesar do ser humano ter capacidade de refletir sobre suas ações, a falta de uma base pedagógica fundamentada pode limitar a extensão desta reflexão no âmbito educacional, especialmente sobre aspectos relativos ao processo ensino-aprendizagem.

\section{O surgimento dos cursos de radiologia no Brasil}

Segundo Oliveira (2013), o trabalho em radiologia inicia-se no Brasil, no final do século XIX, período marcado pela intensificação do desenvolvimento de diversas áreas científicas que contribuiu para inúmeras inovações tecnológicas que alteraram de forma significativa o cotidiano da sociedade. A rápida disseminação das práticas e estudos da radiologia não foi acompanhada por um processo de educação formal para os trabalhadores da área. Durante a primeira metade do século $X X$, os cursos de formação eram ofertados de forma pontual, predominando a formação em serviço.

A primeira aula de radiologia, no Brasil, foi ministrada na Bahia, na Faculdade de Medicina, pelo médico João Américo Garcez Fróes, para a turma do curso de medicina. Em 1913, o médico Rafael de Barros inicia um curso de radiologia na Santa Casa de Misericórdia, em São Paulo; neste mesmo ano, o médico Roberto Duque Estrada ministrava a primeira aula de radiologia na Santa Casa de Misericórdia do Rio de Janeiro, que deu origem a um curso de radiologia para médicos em 1916 com aulas práticas e teóricas (FRANCISCO et al., 2006).

Em 1930, outros dois cursos foram criados, um na Faculdade de Ciências Médicas pelo médico Manuel Dias de Abreu, criador da 'roentgenfotografia', e que, após o I Congresso Nacional de Tuberculose, passou a ser denominada 'abreugrafia'; outro foi o da Faculdade de Medicina do Instituto Hahnemanniano, atual Hospital Gaffrée Guinle, pelo médico José Guilherme Dias Fernandes, ambos no Rio de Janeiro, como observam Francisco et al. ( 2006).

Segundo Ferreira (2010), as primeiras escolas para formação do "Operador de Raios X", localizavam-se no Rio de Janeiro e eram reduzidas, limitavam-se a formar trabalhadores que detinham o ensino formal em nível da então quarta série do ensino elementar para o exercício da atividade. Na década de 60 a exigência da escolaridade para a formação desses trabalhadores passa para o ensino fundamental. Nesta mesma década é criada a Federação das Associações dos Técnicos de Raios $X$ dos Estados do Brasil (FATREB).

Os cursos técnicos expandiram-se com a regulamentação da lei n. 9.394/96 (LDB), pois são autorizados os cursos técnicos subsequentes ao ensino médio, regulamentando a Educação Profissional Técnica e Nível Médio (EPTMN), consequentemente permitindo a expansão das escolas-curso para formação 
técnica isolada, alcançando os egressos do ensino médio e os trabalhadores que necessitavam de requalificação para se adequarem ao mercado.

Nesse sentido, a procura por docentes aumentou, os programas de licenciatura já não supriam a demanda e a experiência em serviço passa a ser um dos únicos requisitos à prática docente no âmbito da educação profissional. Desta forma, por falta de critérios de admissão, os professores que se inseriam nestes cursos não eram devidamente qualificados para a docência. Identifica-se assim, na formação dos professores da educação superior, dentre outras questões, a dificuldade de se atualizarem em suas áreas profissionais, demostrando uma necessidade de uma formação pedagógica continuada (SANTOS; OLIVEIRA, 2016).

Isso é bastante observado no campo da Radiologia, onde os professores são, em sua maioria, Tecnólogos e Bacharéis, e os cursos exigem, na maioria das vezes, apenas conhecimento específico do docente. Os cursos superiores exigem mais em termos de titulação que não necessariamente, precisa ser voltada para a docência. Este fato torna a sala de aula um laboratório para que os docentes sem formação pedagógica desenvolvam, através da experiência suas práticas didáticopedagógicas, sem uma base teórica inicial.

\section{Práticas didático-pedagógicas dos professores de radiologia}

É atribuído ao professor do ensino superior a responsabilidade de formar profissionais competentes para suprir as necessidades do mercado de trabalho. A este docente cabe saber o conteúdo, conhecer os recursos pedagógicos e as novas tecnologias para compartilhar conhecimento ao mesmo tempo que promove o desenvolvimento de habilidades e competências em seus alunos. O desafio é em atender às expectativas e responsabilidades incumbidas a este sujeito com as deficiências e precariedades existentes no processo de formação inicial dos professores universitários (PEREIRA, 2015).

As mudanças ocorridas no mundo do trabalho levaram a transformações nas relações sociais e consequentemente nas formas como se dá a prática docente, ou seja, exigem da educação um outro olhar para o ensinar e o aprender. Dessa forma, compete ao professor, criar alternativas para o conhecimento dos alunos em relação ao meio que os cerca. Se o mundo organizacional exige competência, é necessário que o professor encontre o equilíbrio entre teoria e prática, proporcionando ao aluno conhecer, compreender o mundo e o agir sobre ele (FOGAÇA, 2017).

Diante dessas mudanças, fica cada vez mais aparente a fragilidade do modelo de ensino tradicional, ou de transmissão, centrado na figura do professor como sujeito que detém e transmite o conhecimento. Percebe-se, portanto, a necessidade de modelos pedagógicos que possibilitem a construção ativa do conhecimento que deverá estar presente em toda a vida profissional. Tal contexto aponta novas perspectivas para o ensino, pois identificam-se na atualidade práticas educativas que assumem a construção do conhecimento como traço definidor da apropriação da informação e explicação da realidade (LEÃO, 2009).

Nesse sentido, as metodologias problematizadoras surgem como alternativas já que 0 ensino tradicional parece ter atingido seu esgotamento diante das exigências dos profissionais de saúde e da sociedade. A pedagogia da 
problematização tem sido necessária e incorporada nas práticas pedagógicas da educação de forma geral, pois o termo problematização envolve um dos caminhos para construir situações de aprendizagem significativa cuja proposta trabalha intencionalmente com problemas para o desenvolvimento dos processos de ensinar e aprender (LEÃO, 2009).

Esta metodologia designa um tipo de estratégia de ensino que se baseia em observação da realidade, reflexão e ação tendo destaque a relação ensinoserviço. Enfatiza-se o aprender fazendo, e a aprendizagem que decorre do trabalho em grupos e com a equipe multiprofissional, portanto se encaixa nas práticas reflexivas, como bem observa Leão (2009).

$\mathrm{O}$ ato de ensinar exige que o que é proposto tenha significado para o aluno. Assim, o professor precisa fazer com que o discente entenda a importância e o sentido do que está aprendendo. Dessa forma, há necessidade das práticas reflexivas por parte do professor para que este possa proporcionar o desenvolvimento das competências de seus alunos, pois isto, segundo Fogaça (2017), oferece oportunidade mais ampla e mais direcionada a questões essenciais que permitem chegar a este objetivo.

O corpo docente dos cursos superiores de Tecnologia em Radiologia é composto, geralmente, por profissionais-professores, ou seja, profissionais recrutados do mercado para "ensinar a trabalhar", já que são dotados de conhecimento técnico e científico; porém, diferente dos professores de formação, é evidente a falta de uma base teórica de conhecimentos pedagógicos que se tornam empecilhos para uma prática docente mais sólida, predominando a reprodução das práticas laborais nas salas de aula ou em oficinas-modelo, implantadas nas próprias escolas (SANTOS, 2015).

Estes professores trazem como diferencial de sua formação a bagagem de experiências profissionais vivenciadas na prática, ou obtidas em seu curso inicial de formação para o trabalho. Assim, a ausência do caráter pedagógico e científico dificulta, por vezes, a construção de novos conhecimentos e sua problematização com as situações reais de trabalho (SANTOS, 2015).

As Diretrizes Curriculares Nacionais dos cursos superiores de Tecnologia em Radiologia formulada pelo Conselho Nacional de Técnicos em Radiologia preconizam que o Tecnólogo em Radiologia poderá atuar na educação nos processos que envolvem a formação profissional técnica de nível médio e superior, bem como na educação continuada e permanente em serviço, nos projetos de extensão, no assessoramento em assuntos educacionais ligados à tecnologia radiológica. Pode ainda atuar na docência, devendo concluir a licenciatura em educação profissional ou desenvolver programa de pós-graduação na área da docência em educação profissional ou de docência do ensino superior.

Santos e Oliveira (2016) observam que nos cursos de Radiologia existem, em geral, 4 tipos de professores: o recém-formado dos cursos técnicos ou superiores de tecnologia; o instrutor oriundo dos postos de trabalho, bacharel/tecnólogo e os licenciados nas áreas da saúde e afins, que atuam na Radiologia.

Os profissionais recém-formados tem prática docente que tende a se pautar na transmissão de seus conhecimentos teóricos por meio de aulas expositivas e preleção, objetivando articular o conteúdo apreendido em sua formação com o material técnico dentre livros e outras ferramentas, selecionado para as aulas. 
Este é o modelo que Paulo Freire denomina de bancário, no qual se transfere ou deposita os conteúdos na "conta" de seus alunos, para que sejam devolvidos nas avaliações e o método imitativo em que se reproduz a prática dos colegas mais experientes ou dos professores que carregam como referência de sua própria formação (SANTOS; OLIVEIRA, 2016).

Porém, como observam Santos e Oliveira (2016), esta forma de atuação não atenderia efetivamente às necessidades dos estudantes. Primeiro porque aponta a ausência de fundamentos pedagógicos na formação desse professor; nesse caso a falta de uma formação docente limita a prática didático-pedagógica, o que não contribuiria para o aprendizado dos alunos; segundo porque a falta de experiência do professor com a prática em serviço prejudica a associação da teoria ensinada com a prática efetiva no campo profissional.

Muitos docentes são inseridos no quadro de funcionários como um ato de simples indicação ou aproveitamento imediato depois de formados para ministrar aulas. Neste mesmo grupo de professores é comum ocorrer incompatibilidade entre formação acadêmica e disciplina ministrada, como também a intensa pluralidade de disciplinas em áreas diferentes a serem lecionadas. Essa prática, segundo Ferreira (2010), pode acarretar dificuldades no processo de aprendizagem do corpo discente.

Nas aulas de instrutores provenientes dos postos de trabalho, costuma-se reproduzir os protocolos e rotinas desenvolvidas nos serviços de imagem, isso porque este técnico dispõe apenas de sua experiência acumulada ao longo dos anos. Essa lógica desencadeia em sala uma proposta pedagógica que pretende apenas "ensinar a trabalhar", limitando o conhecimento técnico-científico às necessidades do posto de trabalho e conformando o ensino ao processo produtivo. Essas práticas-pedagógicas tenderão a reduzir cada vez mais o que se aprende para se adequar a educação às demandas do mercado, podendo desqualificar tanto 0 processo de formação quanto o próprio trabalhador (SANTOS; OLIVEIRA, 2016).

O professor com formação para a pesquisa (bacharel) ou tecnológica se caracteriza pelo aprofundamento teórico dos conhecimentos em saúde e tecnologia. Geralmente, são físicos, biomédicos, biólogos, enfermeiros ou tecnólogos em radiologia, com experiência no campo de saúde. Nesse perfil ainda não é possível identificar uma formação pedagógica para o ensino, são poucos os bacharéis que fazem complementação pedagógica para obterem a segunda titulação de licenciado, justamente pelo fato de também se envolverem com pesquisa (SANTOS; OLIVEIRA, 2016).

Para Ferreira (2010), os professores bacharéis normalmente têm como fator complicador a ausência de conhecimentos específicos do campo da radiologia. É comum, por exemplo, pedagogo que ministra disciplina de legislação profissional, ética e noções de psicologia aplicada; enquanto o psicólogo ministra legislação e ética profissional; o fisioterapeuta atuando em protocolos de técnica radiológica; e, o tecnólogo em radiologia ensinando noções de física e de proteção radiológica. Dessa forma, entende-se que essa ausência de conhecimentos específicos dificulta o ensino em disciplinas gerais comuns ao campo da saúde e específicas como técnicas radiológicas.

O profissional graduado com licenciatura em outro campo da saúde ou em outra área, parece desenvolver uma prática docente limitada pela falta de

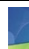


conhecimentos específicos, com dificuldades em conduzir suas aulas por falta de conhecimentos de ordem teórica e prática do trabalho com técnicas radiológicas, mesmo com todo o aporte de sua formação acadêmica. Portanto, a falta de uma formação básica em Radiologia, dificulta seu trabalho docente nos cursos da área, tanto em disciplinas gerais como em disciplinas específicas (SANTOS; OLIVEIRA, 2016).

Valoriza-se nos cursos de Tecnologia em Radiologia, o currículo prático do professor, já que nas aulas há grande interesse por parte dos alunos pelos relatos de vivências dos profissionais já estabelecidos. As universidades apostam na contratação de seus docentes na formação que trazem, assim, as habilidades profissionais adquiridas em anos de prática não são entendidas da mesma forma que o título teórico alcançado, ainda que estas habilidades possam representar diferenciais positivos para a docência (MOREIRA, 2015).

Verifica-se neste meio acadêmico a prática de mercado como legitimadora da capacitação de professores para lecionar em cursos de Tecnologia em Radiologia. Grande parte das instituições solicita que sua confirmação seja aliada apenas ao título. Dessa forma, a experimentação tão enriquecedora dos encontros de ensino não é entendida como característica suficiente para a função. O fluxo dos saberes, baseado nas suas diferenças e complementações, deve ser tanto aceito quanto incentivado. O professor com experiência na área que leciona favorece um acesso mais fácil às questões que serão vivenciadas no exercício da profissão dinâmica dos cursos tecnólogos, mas o domínio das práticas pedagógicas faz com que o processo ensino-aprendizagem ocorra de fato (MOREIRA, 2015).

Nesse sentido, uma capacitação pedagógica que apenas complemente a formação do profissional das técnicas radiológicas e o habilite ao ensino, não é suficiente. É necessária uma nova concepção de formação docente, cujos princípios sejam a recontextualização de sua formação inicial e o aprofundamento teórico-metodológico dos conhecimentos em sua formação profissional além da aquisição de conhecimentos pedagógicos, abrangendo dimensões sociais e culturais (SANTOS; OLIVEIRA, 2016).

\section{Considerações finais}

Os professores do curso de Tecnologia em Radiologia não têm disciplinas voltadas à docência em sua graduação, não sendo preparados para atuarem como professor na sua formação inicia. Dessa forma, é importante entender que a falta de uma base pedagógica fundamentada pode limitar a extensão desta reflexão no âmbito educacional, especialmente sobre aspectos relativos ao processo ensino-aprendizagem.

Os docentes do curso de Tecnologia em Radiologia trazem como diferencial de sua formação a bagagem de experiência profissional vivenciada na prática ou as experiências obtidas em seu curso inicial de formação para o trabalho. Valoriza-se nesses cursos, o currículo prático do professor, já que nas aulas há grande interesse por parte dos alunos pelos relatos de vivências dos profissionais já estabelecidos. Além disso, a prática de mercado é legitimadora da capacitação destes professores.

A ausência do caráter pedagógico e científico dificulta, por vezes, a construção de novos conhecimentos e sua problematização com as situações reais do trabalho 
docente. Nesse sentido, uma capacitação pedagógica que apenas complemente a formação do profissional das técnicas radiológicas e o habilite ao ensino, não é suficiente. É necessária uma nova concepção de formação docente, cujos princípios sejam a recontextualização de sua formação inicial, o aprofundamento teórico-metodológico dos conhecimentos em sua formação profissional, além da aquisição de conhecimentos pedagógicos, abrangendo dimensões sociais e culturais.

Diante disso, entende-se que a formação pedagógica para o trabalho docente é de extrema importância, ainda que o professor carregue consigo conhecimentos específicos adquiridos na formação inicial, ou mesmo, seja dotado de conhecimento prático adquirido nos postos de trabalho. Ao mesmo tempo, o conhecimento pedagógico isoladamente não consegue tornar o processo ensinoaprendizado eficaz, uma vez que o domínio técnico e científico colabora ativamente com a construção das bases tecnológicas repassadas aos discentes. Portanto, o professor do curso de Tecnologia em Radiologia precisará unir conhecimento científico, técnico, prático e pedagógico para aprimorar o desempenho em seu trabalho docente.

\section{Referências}

ALARCÃO, I. Professor-investigador: Que sentido? Que formação? In: B. P. Campos (Org.). Formação profissional de professores no ensino superior. Porto: Porto Editora, Vol. 1, pp. 21-31, 2003.

\section{ALMEIDA, M. I.; PIMENTA, S. G. A construção da pedagogia universitária no} âmbito da Universidade de São Paulo. Pedagogia universitária: caminhos para a formação de professores. São Paulo, Cortez: 2011.

CARVALHO, O. F.; SOUZA, F. H. M. S. Formação do docente da educação profissional e tecnológica no brasil: um diálogo com as faculdades de educação e o curso de pedagogia. Educ. Soc., Campinas, v. 35, no. 128, p. 629-982, jul.-set., 2014. Disponível em: <https://www.scielo.br/pdf/es/v35n128/0101-7330-es-35-12800883.pdf>. Acesso em: 6 novembro 2018

BRASIL. CNE - CONSELHO NACIONAL DE EDUCAÇÃO CNE/CP n 7/2020. Diretrizes Curriculares Nacionais para a Educação Profissional e Tecnológica, a partir da Lei no 11.741/2008, que deu nova redação à Lei de Diretrizes e Bases da Educação Nacional (LDB). Distrito Federal: CNE, 2020.

CONTER - CONSELHO NACIONAL DE TÉCNICOS EM RADIOLOGIA. Documento base para as diretrizes curriculares nacionais dos cursos superiores de tecnologia em radiologia. Distrito Federal: Conae, 2018.

FERREIRA FILHO, J. L. Formação do profissional de radiologia em nível técnico na Região metropolitana do rio de janeiro: Um estudo exploratório. 2010, 100f. Dissertação (Mestrado Profissional em Educação Profissional em 
Saúde) - Escola Politécnica de Saúde Joaquim Venâncio, Fundação Oswaldo Cruz, Rio de Janeiro, 2010.

FOGAÇA, M. R. J. Professores bacharéis, sem formação pedagógica formal e "bem sucedidos" na docência da educação profissional. 2017. Dissertação (Mestrado em Educação) - Universidade do Vale do Rio Dos Sinos, São Leopoldo.

FRANCISCO, F. C. et al. História da Radiologia no Brasil. Rev Imagem, São Paulo, v. 28, n. 1, p. 63-66, 2006.

LEÃO, L. M. P. A prática pedagógica nos cursos de Educação profissional técnica de nível Médio em saúde: a percepção do professor. 2009. Dissertação (Mestrado em Saúde Pública) - Escola Nacional de Saúde Pública Sérgio Arouca, Fundação Oswaldo Cruz, Rio de Janeiro, 2009.

LIMA, E. F. Análise de necessidades formativas de docentes ingressantes numa universidade pública. Ver. Bras. Estud. Pedaog. (online), Brasília, v. 9, n. 243, p. 343-358, maio/ago, 2015. Disponível em:

https://www.scielo.br/pdf/rbeped/v96n243/2176-6681-rbeped-96-243-00343.pdf

Acesso em: Acesso em: 16 nov. 2018.

LUCCHESI, M. A. S. O ensino superior brasileiro e a influência do modelo francês. In: Anais do XI Colóquio Internacional sobre gestão universitária na América do Sul e II Congresso Internacional - IGLU. Florianópolis, 7 e 9 de dezembro de 2011.

MASETTO, M. T. Professor universitário: um profissional da educação na atividade docente. In: MASETTO, Marcos Tarcísio (Org.). Docência na universidade. Campinas, SP: Papirus, 1998.

MOREIRA, L. D. O profissional de mercado como docente nos cursos tecnólogos. 2015. Dissertação de Mestrado (Humanidades, Cultura e Artes) Universidade do Grande Rio "Prof. José de Souza Herdy", Duque de Caxias, 2015.

OLIVEIRA, S. R. et al. Qualificação dos Técnicos em Radiologia: história e questões atuais. Trabalhadores Técnicos da Saúde: aspectos da qualificação profissional do SUS. Rio de Janeiro, Escola Politécnica de Saúde Joaquim Venâncio, 2013.

OLIVEIRA, V.S., SILVA, R.F. Ser bacharel e professor: dilemas na formação de docentes para a educação profissional e ensino superior. vol. 2, 2012, p. 193-205. Instituto Federal de Educação, Ciência e Tecnologia do Rio Grande do Norte Natal, Brasil. Disponível em: https://doi.org/10.15628/holos.2012.913.

Acesso em: 16 nov. 2018. 
PEREIRA, L.R. A prática pedagógica do professor bacharel no curso de administração. 2015. 85 f. Dissertação de Mestrado (Educação) - Pósgraduação em Educação, Universidade do Vale do Sapucaí, Pouso Alegre, 2015.

SANTOS, R. O. Um Olhar sobre os Docentes dos Cursos Técnicos em Radiologia. Anais do III Colóquio nacional / Eixo temático III - Formação de professores para a educação profissional. ISSN: 2358-1190, 2015.

SANTOS, R. O.; OLIVEIRA, S. R. As práticas docentes nos cursos técnicos de Radiologia: uma análise empírica. Rev Academus, Rio de Janeiro, v. 1, n.1, 2016. Disponível em:

http://www.rio.ri.gov.br/dlstatic/10112/6089475/4159720/RevistaAcademus online. pdf. Acesso em: Acesso em: 16 nov. 2018.

SIEWERDT, R.; RAUSCH, R. B. Formação docente de professores que atuam nos cursos superiores de tecnologia. Formação Docente - Revista Brasileira de Pesquisa sobre Formação de Professores, v. 4, n. 6, p. 98-114, 20 jun. 2018. . Disponível em:

http://www.ucs.br/etc/conferencias/index.php/anpedsul/9anpedsul/paper/viewFile/8 61/445. Acesso em: Acesso em: 16 nov. 2018.

Recebido: $30 / 07 / 2020$

Aprovado:.10/03/2021

Como citar: SILVA, E. N. D.; JUNIOR, E. F. S. O.; FERRO, M. G. D. Formação e prática didáticopedagógicas de professores dos cursos de Tecnologia em Radiologia. Revista de Estudos e Pesquisas sobre Ensino Tecnológico (EDUCITEC), v. 7, e137021, 2021.

Contribuição de autoria:

Érica Natasha Duarte Silva - Conceituação, Curadoria de dados, Análise Formal, Investigação, Administração do projeto, Recursos, Supervisão, Validação, Visualização, Escrita (rascunho original), Escrita (revisão e edição).

Ednaldo Francisco Santos Oliveira Junior - Curadoria de dados, Análise Formal, Metodologia, Administração do projeto, Recursos, Supervisão, Validação, Escrita (revisão e edição).

Maria da Glória Duarte Ferro - Metodologia, Recursos, Supervisão, Validação, Escrita (revisão e edição).

Direito autoral: Este artigo está licenciado sob os termos da Licença Creative CommonsAtribuição 4.0 Internacional.

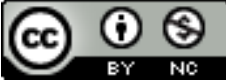

